\title{
Decoupled radiogenic Nd-Hf isotopes of clays reveal Miocene changes in South Asian Monsoon weathering
}

\author{
ED HATHORNE ${ }^{1}$, LISA BRETSCHNEIDER ${ }^{1}$, MARTIN \\ FRANK $^{1}$ AND GERMAIN BAYON ${ }^{2}$ \\ ${ }^{1}$ GEOMAR Helmholtz Centre for Ocean Research Kiel \\ ${ }^{2}$ IFREMER
}

Presenting Author: ehathorne@geomar.de

Enhanced removal of atmospheric $\mathrm{CO}_{2}$ by silicate weathering in the tropics and during orogenic erosion and weathering potentially contributed to global cooling in the Cenozoic. The South Asian Monsoon region experienced both active Himalayan tectonics and a tropical climate during the global carbon cycle changes and cooling of the Miocene.

The radiogenic isotopes of hafnium and neodymium are decoupled during silicate weathering with the isotopic composition of river clays being offset from bulk rocks and coarser sediments [1]. Here we examine decoupled Nd-Hf isotope signatures of clays deposited in marine sediments of the southern Bay of Bengal (IODP Site U1443) across the middle to late Miocene to infer changes in silicate weathering intensity. The deviations of the Hf isotope compositions from the array defined by global river clays ( $\Delta \varepsilon H f$ clay) represent some of the highest values measured to date suggesting the prevalence of extremely intense chemical weathering during the Miocene. Comparison with modern weathering environments indicates that these extreme values unlikely resulted from extremely warm and wet climate conditions but instead that clays produced by silicate weathering incorporated highly radiogenic Hf signatures from specifically labile mineral phases. The extremely high $\Delta \varepsilon H f$ clay values found in the marine sediments likely resulted from intense weathering of the sediments that were then eroded and transported to Site U1443 via rivers. The $\Delta \varepsilon H f$ clay values decreased during the late Miocene, signalling a decrease in weathering intensity or erosion and transport of intensely weathered clays. This possibly occurred in response to global cooling and aridification associated with grassland expansion but $\Delta \varepsilon \mathrm{Hf}$ clay values still indicate a warm and wet weathering regime [1]. Alternatively, enhanced erosion may have prevented the formation of old and highly weathered surfaces at the time, which were likely a prerequisite for the exceptionally high middle Miocene $\triangle \varepsilon \mathrm{Hf}$ clay values.

[1] Bayon et al. (2016) EPSL 438, 25. 